\title{
Post-Harvest Handling Practices and Losses for Legumes and Starchy Staples in Uganda
}

\author{
Juliet E. Tibagonzeka1, Grace Akumu', Florence Kiyimba², Abel Atukwase1, Julius Wambete1, \\ Joseph Bbemba ${ }^{3}$, John H. Muyonga ${ }^{*}$
}

\author{
${ }^{1}$ School of Food Technology, Nutrition \& Bioengineering, Makerere University, Kampala, Uganda \\ ${ }^{2}$ National Agricultural Research Organization, Entebbe, Uganda \\ ${ }^{3}$ Volunteer Efforts for Development Concern, Kampala, Uganda \\ Email: ^hmuyonga@yahoo.com
}

How to cite this paper: Tibagonzeka, J.E., Akumu, G., Kiyimba, F., Atukwase, A., Wambete, J., Bbemba, J. and Muyonga, J.H. (2018) Post-Harvest Handling Practices and Losses for Legumes and Starchy Staples in Uganda. Agricultural Sciences, 9, 141-156.

https://doi.org/10.4236/as.2018.91011

Received: May 30, 2017

Accepted: January 28, 2018

Published: January 31, 2018

Copyright (๑) 2018 by authors and Scientific Research Publishing Inc. This work is licensed under the Creative Commons Attribution International License (CC BY 4.0).

http://creativecommons.org/licenses/by/4.0/

\begin{abstract}
High postharvest losses in developing countries negate the efforts geared towards improving food security. Poor produce quality including high prevalence of mycotoxin contamination is another significant problem. Appropriate postharvest handling and processing provide opportunities to reduce postharvest losses and improve food safety. This study was aimed at establishing the postharvest handling practices and estimating qualitative and quantitative postharvest losses for maize, millet, sorghum, beans, groundnuts, cassava, and sweet potatoes among farmers in 3 districts (Kamuli, Apac and Nakasongola) in Uganda, representing different agro-ecological zones. The study was done in late August 2014 after the first season harvests (June-August). Farmer interviews, focus group discussions and key informant interviews were used to collect data on postharvest loss estimates and postharvest handling practices. Samples of the different foods were collected and analyzed for physical quality characteristics, mould count and aflatoxin contamination using standard laboratory procedures. The results show predominance of rudimentary and inappropriate postharvest handling methods. Postharvest loss estimates were generally high, with values of $41 \%$, $33 \%, 33 \%, 26 \%, 31 \%, 22 \%, 17 \%$ and $19 \%$ for maize, millet, sorghum, beans, groundnuts, cowpea, sweet potatoes and cassava respectively. The highest loss for all the crops was recorded at storage. Prevalence of aflatoxin contamination was $44 \%, 91 \%, 55 \%, 36 \%, 35 \%$ and $60 \%$ for maize, sorghum, groundnuts, millet, sweet potatoes and cassava respectively. Sorghum, maize and groundnuts were found to have the highest aflatoxin contamination levels. Chi-square test $(p=0.024$, odds ratio $=5)$ showed that grain dried on bare ground had higher aflatoxin levels than that dried on a covered surface. The findings of this study reveal a serious need for postharvest interventions
\end{abstract}


as a strategy to address food security.

\section{Keywords}

Aflatoxins, Mould Contamination, Postharvest Losses, Postharvest Practices, Grain Storage, Crop Drying

\section{Introduction}

The post-harvest system encompasses a sequence of activities and operations that can be divided into two groups: the technical activities (including harvesting, field drying, threshing, cleaning, additional drying, storage, processing, and quality control) and economic activities (including transporting, marketing, information and communication, administration and management). Crops cannot be improved after harvest, but proper practices can improve stability and reduce negative changes that result in produce deterioration. Post-harvest loss (PHL) is a measurable quantitative and qualitative loss of a product at any moment during the post-harvest chain and includes the change in the availability, edibility, wholesomeness or quality of the food that prevents its consumption [1] [2]. Aflatoxin contamination of agricultural produce is a big problem, with aflatoxin $\mathrm{B}_{1}$ being the most prevalent [3]. Aflatoxin contamination of key staples can affect each of the four pillars of food security (availability, access, utilization, and stability). Contamination in staples such as maize, sorghum and groundnuts can directly reduce availability of food since highly contaminated food is not suitable for human consumption. Producers of the affected crop may also earn less because of product rejection, reduced market value, or inability to gain access to the higher-value international trade market. Lower farmer income in turn limits ability to purchase food for the family, which translates into reduced access to food. For years now, Uganda has been referred to as the food basket of the east and central African region. Ironically, today, the country is among the many in the world that are grappling with consistent food insecurity and nutritional deficiency. A significant percentage of Uganda's population still suffers from hunger. According to von Grebmer et al. [4], Uganda has a Global Hunger Index (GHI) score of 16.7, placing it $42^{\text {nd }}$ out of 81 countries ranked in 2011, with its hunger situation considered serious. The Ministry of Agriculture, Animal Industry and Fisheries (MAAIF) partly attributes the problem of food insecurity to poor post-harvest handling, which results in losses. Presently, according to the MAAIF [5], Uganda processes a low percentage of its agricultural produce. Perishable farm produce are wasted or sold at give-away prices due to inadequate post-harvest facilities and lack of effective processing or preservation techniques. Post-harvest losses in Sub-Saharan Africa are estimated at 5\% - 13\% for cereals, $12 \%-18 \%$ for oilseeds and pulses and $13 \%-29 \%$ for root and tuber crops [6]. If saved, this would go a long way in contributing to food security. The aim of this 
study was to provide information about the prevailing post-harvest knowledge, handling practices and losses for main staple crops produced in Uganda (maize, millet, sorghum, grain amaranth, beans, groundnuts, cowpeas, sweet potatoes and cassava).

\section{Materials and Methods}

\subsection{The Study Area}

The study was conducted in three districts of Uganda, namely: Nakasongola, Kamuli and Apac in late August 2014 after the first season harvests (June-August) These districts represent 3 of Uganda's agro-ecological zones: the Pastoral rangelands, Kioga plains and the North Western Savannah grasslands, respectively. The study covered all sub-counties with significant production of any of the 9 crops considered in this study. The sub-counties chosen included Butansi, Bugulumbya, Namasagali, Kisozi, town council and Bugaya (Buyende) in Kamuli district; Kakooge, Wabinyonyi, Lwabiyata and Lwampanga in Nakasongola district and Aduku, Apac town council, Ibuje, Chegeere and Aboke (in Kole) in Apac district.

\subsection{Sample Size}

In order to get sample size for each district (each district was a different stratum), proportions $\left(W_{h}\right)$ for each district of the total population $\left(N_{n}\right)$ were calculated (Table 1). To increase the small size of sample in Nakasongola (i.e. 41) and to allow within districts estimates, non-proportionate sampling was used, as we could not sample much more than 400 people. Nakasongola sample size was increased to 100 , resulting in a sample: total households ration of 202:1 since the district is estimated to have a total of 20,241 households. The total sampled households for both Apac and Kamuli was 500:1. The non-proportionate sampling could only be corrected by giving each observation a weight. The actual sample size with all consideration in mind was 485 . Proportions of each district were multiplied by the supposed sample size by multiplying population of each stratum by the sampling fraction (Sampling fraction; $f=$ Supposed sample size; $n_{s} /$ Total population for the 3 districts; $\left.N_{n}=400 / 199,702=0.002\right)$. For each of the

Table 1. Sample size calculations.

\begin{tabular}{ccccccc}
\hline $\begin{array}{c}\text { Strata } \\
\text { (District) }\end{array}$ & $\begin{array}{c}\text { Population/ } \\
\left(N_{h}\right)^{* *}\end{array}$ & $W_{h}=N_{h} / N_{n}$ & $\begin{array}{c}\text { Sample (calculated } \\
\text { from the Supposed) } \\
n_{c}=W_{h}{ }^{*} n_{s}\end{array}$ & $\begin{array}{c}\text { Sample size after } \\
\text { increasing Nakasongola } \\
\text { sample size }\end{array}$ & $\begin{array}{c}\text { Expansion weight } \\
\text { (for accurate } \\
\text { estimations) }\end{array}$ & $\begin{array}{c}\text { Actual sample } \\
\text { size considering } \\
\text { non responses }\end{array}$ \\
\hline Apac & 81,939 & 0.41 & 164 & 164 & 200 & 176 \\
Kamuli & 97,522 & 0.49 & 195 & 195 & 500 & 200 \\
Nakasongola & 20,241 & 0.1 & 41 & 100 & 500 & 109 \\
Total $\left(N_{n}\right)$ & 199,702 & 1 & 400 & 459 & $\mathbf{4 8 5}$ \\
\hline
\end{tabular}

**Agricultural Households and holding characteristics report (UBOS, 2010)-Uganda census of agriculture 2008/2009. $W_{h}=$ Proportion of each stratum to the total population; $N_{h}=$ Population of each strata; $f=$ Sampling fraction; $n_{c}=$ Calculated sample before increasing population of Nakasongola; $n_{s}=$ Supposed sample size; $N_{n}=$ Total population of all the strata. 
3 districts, 15 questionnaires were added to cater for more than $10 \%$ (11.25\%) of the non-responses.

\subsection{Sampling Strategy}

The sampling techniques used were: stratification by district followed by a two stage (cluster) sampling technique at Sub-county and farmer group levels. Respondents were purposively selected from 21 farmer groups within the 14 selected sub-counties. Only farmers identified by the group to regularly produce at least one of the selected crops were selected. Key informants (16) consisting of traders of foodstuffs, agricultural extension workers and food processors knowledgeable about post-harvest handling of the selected crops were selected purposefully with the help of VEDCO mobilisers across the 14 sub-counties. Fourteen (14) focus group discussions were conducted with farmers.

\subsection{Data Collection}

\subsubsection{Data Collection Instruments}

Semi-structured questionnaires with both closed and open ended questions were used. The questionnaires were pre-tested for reliability. The questionnaires were pre-tested for reliability. Twenty farmers, who were not among the study sample, were selected from Apac, Kamuli and Nakasongola and interviewed twice using the same questionnaire. The interval between the interviews was two weeks to minimise recall of responses in the first interview. Reliability coefficients computed from the responses of respondents at the two different interview times ranged from 0.75 to 0.86 . These values show an acceptable level of reliability. The general convention in research has been prescribed by Nunnally and Bernstein [7], which states that one should strive for reliability values of 0.70 or higher.

\subsubsection{Determination of Current Postharvest Knowledge, Attitudes and Practices}

Information regarding current postharvest knowledge, practices and attitudes was collected through semi-structured questionnaires with farmers, key informant interviews and focus group discussions. A total of 485 farmers and 16 key informants (consisting of traders of foodstuffs, agricultural extension workers and food processors) were interviewed. Fourteen (14) focus group discussions were conducted with farmers.

Before actual data collection, recognizance meetings were held in each of the three districts to familiarize with and get consent from local authorities in the study areas. Consent was sought from individual respondents before each interview. The purpose of the assessment was clearly explained as well as the assurance of confidentiality.

\subsection{Data Analysis and Reporting}

Data analysis was done using Statistical Package for Social Scientists Version 23. 
Descriptive statistics for the different measures (means and standard deviations) were derived and ANOVA followed by LSD used to compare values for different crops. Correlations analysis was undertaken to determine the relationship between farmer attributes and practices. Chi-square analysis was used to determine the factors associated with post-harvest losses while correlation was done to also establish factors associated with PHL.

\subsection{Determination of Quality Attributes}

\subsubsection{Quality of Farmer Produce}

Dry samples (500 g per sample) were collected from every respondent representing a household for as long as the crop sample(s) were among the nine selected by the study. This was done in late August 2014 after the first season harvests (June-August). The samples were packaged in polyethylene bags, sealed and transported to the Makerere University Food Science laboratories for analysis.

\subsubsection{Moisture Content}

Moisture content of the samples was determined using the standard air oven method [8]. The samples were dried at $100^{\circ} \mathrm{C}$ to constant weight and the mean moisture content was calculated on a percentage wet basis.

\subsubsection{Physical Quality Parameters}

The physical quality attributes, including insect damage, foreign matter, shriveled, broken and discoloured were determined by visual inspection and manual separation of the sample.

\subsubsection{Enumeration of Molds}

About thirty kernels of grains from each sample lot were assayed by direct plating technique for internal mold infection [9]. The kernels were surface disinfected for 1 min with sodium hypochlorite (10\% commercial bleach, Jik, Rickitt Benckiser, East Africa Ltd), washed three times with sterile distilled water and placed directly on the surface of potato dextrose agar prepared by mixing $39 \mathrm{~g}$ of powdered potato dextrose agar and 1 liter of distilled water. Ten kernels were placed directly on each agar plate. For cassava and sweet potato, the samples were first milled into flour using a laboratory Blender (Waring commercial blender model HGBTWTS3, Torrington, USA). A 9:1 dilution was prepared by thoroughly suspending $10 \mathrm{~g}$ of each sample in $90 \mathrm{ml}$ of sterile diluent (a quarter strength ringer's solution). This suspension was properly mixed and further dilutions made aseptically. In each case, one milliliter of initial suspension was transferred into $9 \mathrm{ml}$ of diluent successively to make dilutions of $10^{-2}$ to $10^{-5}$. About $0.1 \mathrm{ml}$ of the selected dilutions was surface spread onto the agar using a $90^{\circ}$ glass rod. All the samples were plated in duplicates. The plates were incubated upright at about $25^{\circ} \mathrm{C}$ for 5 days. The plates were incubated upright at $25^{\circ} \mathrm{C}$ for 5 days and then the mold colonies were enumerated. 


\subsubsection{Aflatoxin Analysis}

The aflatest fluorometer procedure (corn procedure was calibrated for all the crops except groundnuts) was used to test for total aflatoxins using AflaTest ${ }^{\oplus} \mathrm{Se}-$ ries-4 EX Fluorometer following the manufacturer's instructions (VICAM, A Waters business 34 Maple Street, Milford, MA 01757, USA). The detection limits were set at 0 parts per billion (ppb) (lowest) and $100 \mathrm{ppb}$ (highest). The kernels were ground using a laboratory blender and from each grain sample, $50 \mathrm{~g}$ of the flour was weighed, mixed with $5 \mathrm{~g}$ sodium chloride and placed in the blender jar. A mixture $(100 \mathrm{ml})$ of methanol and water solution $(80: 20, \mathrm{v} / \mathrm{v})$ was added to the flour and blended at high speed for one minute. The blended mixture was filtered using fluted filter paper and $10 \mathrm{ml}$ of filtrate was pipetted into a clean vessel, diluted with $40 \mathrm{ml}$ of distilled water, mixed thoroughly and filtered through glass microfiber glass filter into a clean glass syringe. From the syringe, $10 \mathrm{ml}$ of the filtered dilute extract $(10 \mathrm{ml}=1.0 \mathrm{~g}$ sample equivalent $)$ was passed through Aflatest ${ }^{\oplus}-\mathrm{P}$ affinity column at a rate of $1 \mathrm{drop} /$ second and the column was rinsed with $10 \mathrm{ml}$ of distilled water twice at a rate of $1-2$ drops of water. The affinity column was eluted by passing $1 \mathrm{ml}$ HPLC grade methanol through column at a rate of 1 drop/second, and the eluent collected in a glass cuvette. One milliliter of Aflatest ${ }^{\circ}$ developer solution was added to the eluent, mixed thoroughly and the cuvette was placed in the fluorometer earlier calibrated to read total aflatoxin. Aflatoxin concentration ( $\mathrm{ppb}$ ) in the samples were detected and recorded after $60 \mathrm{s.}$

For the groundnut samples, the aflatest fluorometer procedure for peanuts, peanut meal and peanut butter was used to test for total aflatoxins using AflaTest ${ }^{\oplus}$ Series-4 EXFluorometer ${ }^{\circledR}$ following the manufacturer's instructions (VICAM, A Waters business 34 Maple Street, Milford, MA 01757, USA). The detection limits were set at 0 parts per billion (ppb) (lowest) and $200 \mathrm{ppb}$ (highest). The kernels were ground using a laboratory blender and from each grain sample, $25 \mathrm{~g}$ of the flour was weighed, mixed with $5 \mathrm{~g}$ sodium chloride and placed in the blender jar. A solution $(125 \mathrm{ml})$ of methanol and water $(80: 20, \mathrm{v} / \mathrm{v})$ was added to the flour and blended at high speed setting using Warring Commercial laboratory blender model HGBTW753 (Torrington CT, US) for one minute; the blended mixture was filtered using fluted filter paper and $20 \mathrm{ml}$ of filtrate was pipetted into a clean vessel, diluted with $20 \mathrm{ml}$ of distilled water, mixed thoroughly and filtered through microfiber glass filter into a clean glass syringe. From the syringe, $5 \mathrm{ml}$ of the filtered dilute extract $(5 \mathrm{ml}=0.5 \mathrm{~g}$ sample equivalent) was passed through Aflatest ${ }^{\oplus}$-Paffinity column at a rate of 1 drop/second and the column was rinsed with $10 \mathrm{ml}$ of distilled water once at a rate of $1-2$ drops of water. The affinity column was eluted by passing $1 \mathrm{ml}$ HPLC grade methanol through column at a rate of 1 drop/second, and the eluent collected in a glass cuvette. One milliliter of Aflatest ${ }^{\oplus}$ developer solution was added to the eluent, mixed thoroughly and the cuvette was placed in the fluorometer earlier calibrated to read total aflatoxin. Aflatoxin concentration ( $\mathrm{ppb}$ ) in 
the samples were detected and recorded after $60 \mathrm{~s}$.

\section{Results and Discussion}

\subsection{Farmers' Socio-Demographics}

Most (72.7\%) of the 485 respondents were aged 18 - 49. Females constituted 65\% $(n=315)$ of the respondents. A high percentage $(71.2 \%, n=352)$ of the respondents had a household size of five or more, indicating a high dependence ratio. The education level for most of the respondents was low, with only $27.3 \%$ ( $n=$ 132) reporting secondary level education. Majority $(84.5 \%, n=410)$ of the respondents belonged to a farmer group. The socio-demographics data points to a high involvement of young to middle age people, dominated by females of relatively low educational level in postharvest handling of crops. This information is important for targeting the design postharvest technologies to the needs of specific users.

\subsection{Importance of Different Crops}

Based on total harvests and the percentage of farmers that grew the crops, the most important crops were found to be maize, millet, beans and cassava for Apac district; maize, beans, sweet potatoes and cassava for Kamuli and Nakasongola. Groundnuts, though not among the top four were grown by more than $36 \%$ of farmers in each of the 3 districts. This ranking shows that the crops covered by this study are very important for the farmers in the three districts.

\subsection{Farmers' Estimates of Postharvest Losses}

Farmers' estimate of postharvest losses varied amongst the different crops and districts (Table 2). Generally, most of the postharvest loss was reported to occur during harvest and during storage. Focus group discussions and key informant

Table 2. Estimates of postharvest losses for different crops by farmers.

\begin{tabular}{cccc}
\hline & & Mean $(\% \pm$ SD) & \\
\hline Crop & Loss at harvest & Loss during transportation & Loss during storage \\
\hline Maize & $16.4 \pm 3.61$ & $0.51 \pm 0.14$ & $24.55 \pm 5.49$ \\
Millet & $13.09 \pm 5.90$ & $0.38 \pm 0.23$ & $19.74 \pm 8.71$ \\
Sorghum & $14.21 \pm 12.47$ & $0.47 \pm 0.39$ & $19.12 \pm 13.64$ \\
G. amaranth & $8.01 \pm 8.04$ & $4.58 \pm 6.71$ & $13.96 \pm 11.08$ \\
Beans & $10.28 \pm 2.21$ & $4.99 \pm 0.16$ & $15.43 \pm 3.33$ \\
G. nuts & $12.27 \pm 1.71$ & $1.31 \pm 0.72$ & $18.87 \pm 2.94$ \\
C. peas & $7.9 \pm 4.81$ & $0.65 \pm 0.34$ & $14 \pm 6.51$ \\
S. potatoes & $15.75 \pm 3.20$ & - & $1.2 \pm 2.01$ \\
Cassava & $15.99 \pm 3.33$ & $0.95 \pm 1.04$ & $3.02 \pm 3.30$ \\
\hline
\end{tabular}

(-) No loss declared by respondents. 
interviews revealed that significant losses also occur during threshing, winnowing, milling, distribution and marketing. The qualitative postharvest forms reported included insect infestation, moulding, change in appearance, sprouting, mixture of varieties and shriveling.

\subsection{Quality of Farmer Produce}

\subsubsection{Physical Characteristics}

Insect damage was found to be a major problem with grains (Table 3). Other relatively significant problems among the physical attributes included contamination with foreign matter and discoloration in the case of cassava and sweet potatoes.

Chi-square test $(p=0.048$, odds ratio $=2.5)$ revealed that insect pest infestation of legumes was higher for farmers who used mixed variety of seeds at planting than those who used single variety of seed at planting. Farmers who mixed old and new seeds at planting also recorded higher pest infestation (Chi-square test, $p=0.028$, odds ratio $=3$ ) than those who used only new seeds at planting. Threshing by beating with sticks was associated with higher breakage as compared to those who threshed by hand (chi square test, $p=0.043$, odds ratio $=4$ ).

For dried cassava and sweet potatoes, mould discoloration an indicator of inappropriate post-harvest handling, ranged from 53\% - 63\%. Discoloration was less prevalent among farmers that had received training on cassava or/and sweet potato processing than those who had not (Chi-square test, $p=0.016$, odds ratio $=5$ ). Farmers who revealed careful selection of only top quality roots and tubers without any signs of damage for processing had dried chips with lower level of discoloration (Chi-square test, $p=0.036$, odds ratio $=3$ ) that those who did not report taking this step.

Table 3. Physical Characteristics of all the collected samples.

\begin{tabular}{|c|c|c|c|c|c|c|c|}
\hline \multicolumn{8}{|c|}{ Mean (\% \pm SD) } \\
\hline Crop & \% Moisture Content & $\%$ Foreign Matter & \% Insect Damage & \% Discolored & $\%$ Broken/Split & $\%$ Shriveled & $\%$ Other Varieties \\
\hline Maize & $14.5 \pm 0.8^{\mathrm{a}}$ & $0.14 \pm 0.05^{\mathrm{a}}$ & $6.14 \pm 6.97^{\mathrm{ab}}$ & $1.62 \pm 0.57^{\mathrm{a}}$ & $0.38 \pm 0.13^{\mathrm{a}}$ & $0.12 \pm 0.02^{\mathrm{a}}$ & $0.16 \pm 0.01^{\mathrm{a}}$ \\
\hline Sorghum & $13.3 \pm 0.42^{\mathrm{a}}$ & $2.29 \pm 0.29^{\mathrm{b}}$ & $3.48 \pm 1.05^{\mathrm{ab}}$ & $0.16 \pm 0.04^{\mathrm{a}}$ & $0.1 \pm 0.06^{\mathrm{a}}$ & $0.05 \pm 0.01^{\mathrm{a}}$ & $1 \pm 1.2^{\mathrm{ab}}$ \\
\hline Millet & $12.3 \pm 0.12^{\mathrm{b}}$ & $4.9 \pm 0.38^{b}$ & $0.05 \pm 0.06^{\mathrm{a}}$ & $1.45 \pm 0.33^{\mathrm{a}}$ & $0.13 \pm 0.02^{\mathrm{a}}$ & $0.02 \pm 0.01^{\mathrm{a}}$ & $1.52 \pm 0.62^{\mathrm{ab}}$ \\
\hline Beans & $13.4 \pm 1.15^{\mathrm{a}}$ & $1.08 \pm 0.74^{\mathrm{a}}$ & $5.1 \pm 4.38^{\mathrm{ab}}$ & $1.37 \pm 0.51^{\mathrm{a}}$ & $0.25 \pm 0.19^{a}$ & $0.46 \pm 0.2^{\mathrm{a}}$ & $5.41 \pm 3.83^{b}$ \\
\hline G. nuts & $13.78 \pm 1.1^{\mathrm{a}}$ & $0.22 \pm 0.1^{\mathrm{a}}$ & $0.9 \pm 0.37^{\mathrm{a}}$ & $2.85 \pm 1.33^{\mathrm{a}}$ & $0.52 \pm 0.42^{\mathrm{a}}$ & $3.22 \pm 1.39^{\mathrm{b}}$ & $2.66 \pm 2.08^{\mathrm{ab}}$ \\
\hline Cowpeas & $13.6 \pm 0.6^{\mathrm{a}}$ & $0.15 \pm 0.02^{\mathrm{a}}$ & $0.9 \pm 0.01^{\mathrm{a}}$ & $3.99 \pm 0.2^{\mathrm{ab}}$ & $0.13 \pm 0.02^{\mathrm{a}}$ & $0.06 \pm 0.04^{\mathrm{a}}$ & $0.6 \pm 0.5^{\mathrm{a}}$ \\
\hline G. amaranths & $11.74 \pm 0.6^{\mathrm{b}}$ & $1.24 \pm 0.73^{\mathrm{a}}$ & $0.02 \pm 0.03^{\mathrm{a}}$ & $0.59 \pm 0.42^{\mathrm{a}}$ & $0.01 \pm 0.01^{\mathrm{a}}$ & $0.14 \pm 0.16^{\mathrm{a}}$ & $0.91 \pm 0.5^{\mathrm{a}}$ \\
\hline Cassava & $11.5 \pm 0.55^{\mathrm{b}}$ & $0.39 \pm 0.57^{\mathrm{a}}$ & $27.1 \pm 17.7^{\mathrm{b}}$ & $59.5 \pm 2.3^{b}$ & - & - & - \\
\hline
\end{tabular}

Means with different superscripts within the same column are significantly different, (-) means not applicable. 


\subsubsection{Aflatoxin and Mould Contamination}

Prevalence of aflatoxin contamination was generally high for all crops analyzed, although the actual levels varied among the districts and crops (Table 4). Sorghum, maize and groundnuts exhibited the highest levels of aflatoxin contamination.

In general, sorghum samples had the highest aflatoxin load $(20.33 \pm 8.62 \mathrm{ppb})$ beyond the acceptable UNBS limit (Not greater than $10 \mathrm{ppb}$ ) [10]. It must be noted that samples that exhibited significant aflatoxin levels did not necessarily show any physical defects. Prevalence of moulds was rather high on the different crops, with sorghum (91\%), maize (88.5\%) and groundnuts (74\%) showing the highest prevalence. The fact that presence of significant aflatoxin levels is not necessarily associated to physical defects presents serious challenges for on-farm assessment/detection of aflatoxin by farmers.

\subsection{Farmer Post-Harvest Practices}

The dominant harvesting and post-harvest handling methods recorded were manual and quite labour intensive. The collation of information gathered by the different survey methods also shows inappropriate postharvest practices with potential to negatively affect produce quality. The following inappropriate postharvest practices were found to be common: use of poor threshing methods, use of inappropriate storage facilities, poor handling during storage (no cleaning and fumigation), use of poor peeling/chipping methods, improper drying surfaces, placement of crop storage containers directly on the ground during storage, lack of testing for adequate drying and inadequate sorting of the crop. These findings point to a need for interventions that promote proper postharvest handling along value chain for the different crops.

\subsection{Transportation}

Transportation of produce was mainly by head (70.1\%) and bicycles (29.2\%). From the focus group discussions, it was revealed that transport was a main

Table 4. Prevalence and levels of aflatoxin contamination.

\begin{tabular}{cccccc}
\hline Crops & \multicolumn{5}{c}{ Aflatoxin content } \\
\hline \multicolumn{5}{c}{$\%$ positive samples } \\
Maize & Total positive & $10-<20 \mathrm{ppb}$ & $>20 \mathrm{ppb}$ & Mean (ppb) & Range (ppb) \\
Sorghum & $44.4^{\mathrm{a}}$ & $9.7^{\mathrm{ab}}$ & $5.1^{\mathrm{ab}}$ & $11.8^{\mathrm{ab}}$ & $0-160$ \\
Groundnuts & $91.7^{\mathrm{b}}$ & $59.7^{\mathrm{b}}$ & $31.8^{\mathrm{b}}$ & $20.3^{\mathrm{b}}$ & $0-28$ \\
Millet & $55.6^{\mathrm{ab}}$ & $5.6^{\mathrm{ab}}$ & $0^{\mathrm{a}}$ & $4.3^{\mathrm{a}}$ & $0-16$ \\
S. potatoes & $36.8^{\mathrm{a}}$ & $0^{\mathrm{a}}$ & $0^{\mathrm{a}}$ & $0.2^{\mathrm{a}}$ & $0-1$ \\
Cassava & $35.1^{\mathrm{a}}$ & $0^{\mathrm{a}}$ & $0^{\mathrm{a}}$ & $1.2^{\mathrm{a}}$ & $0-1.8$ \\
\hline
\end{tabular}

Means with different superscripts within the same column are significantly different. 
constraint to how much farmers can harvest in a day. In general, crops were not stored in the field after harvest in all the 3 districts for fear of theft. As a result, farmers only harvest volumes that they can carry in any one day. Considering that the main means of transportation from the garden was by head, the amounts that can be transported within a given time frame is limited. As a result, the produce may be exposed to rewetting in case of rains. These findings seem to imply that a transport intervention may go a long way in reducing the losses that occur at harvest before or as crops leave the fields. In assessing interventions targeted to reduce transport constraints, their impact on these field losses needs to be assessed.

\subsection{Drying}

Sun drying on bare ground was found to be the main method of crop drying, with a prevalence of $93.2 \%$ (Figure 1 ). Farmers stated that they experienced difficulties in drying crops during rainy seasons. To address this problem, some farmers were found to dry cassava chips above cooking areas in the kitchen. Unfortunately, this causes discoloration. Given that the study areas get reasonable length of dry seasons, timely harvest and drying may be the most prudent recommendation, as alternative drying technologies may not be affordable to resource constrained farmers.

Chi square test $(p=0.024$, odds ratio $=5)$ revealed that samples of sorghum and maize which were dried on bare ground were more likely to have a high load of aflatoxins ( $>6 \mathrm{ppb}$ ) than those dried on lined surfaces.

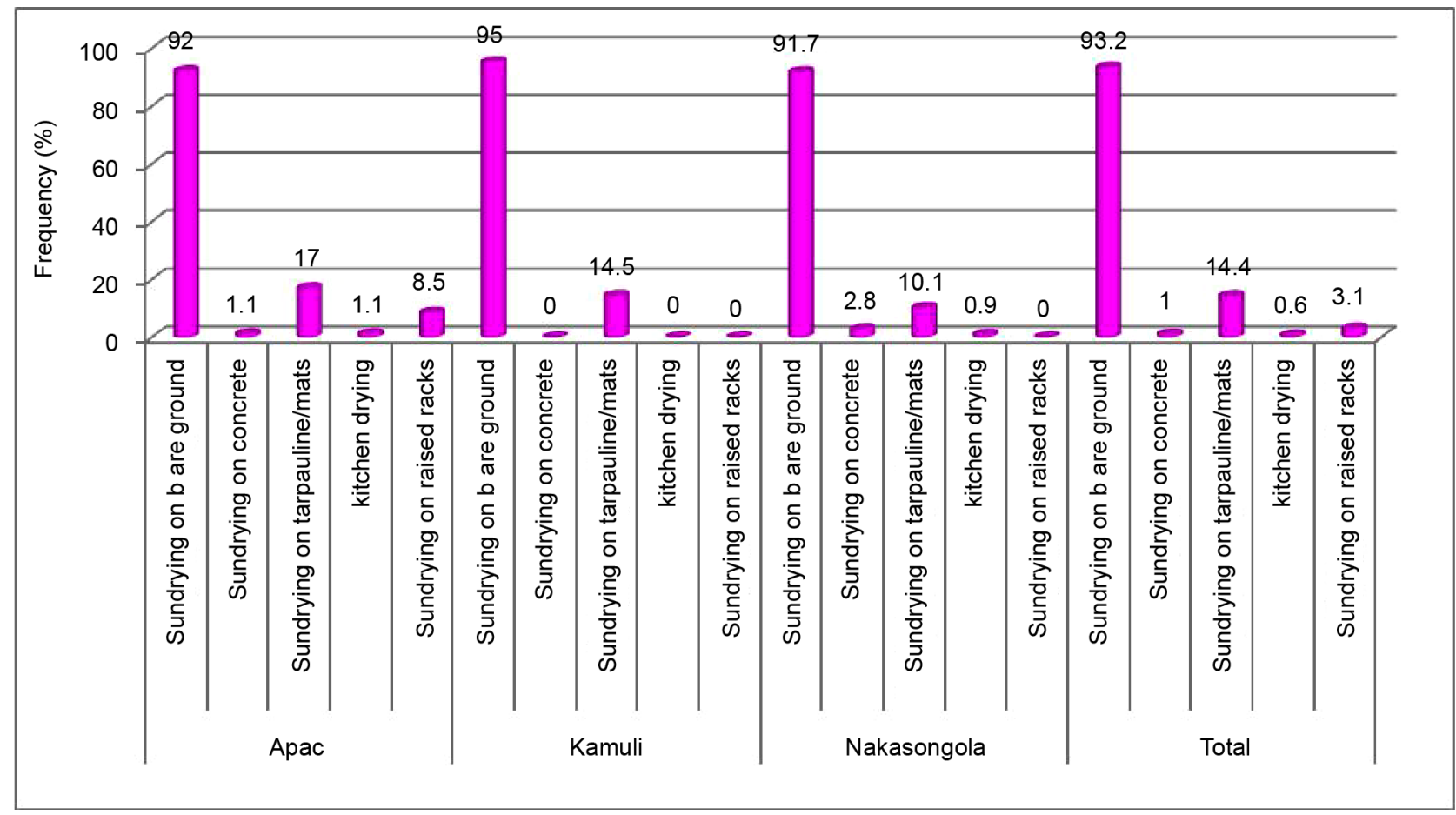

Figure 1. The various treatment methods used during home drying. 


\subsection{Threshing and Shelling}

All farmers threshed grain manually, with $46 \%$ beating the crop with a stick (Figure 2). Maize and beans were generally reported to be manually shelled/ threshed by beating the crop with a stick. This method results in splitting and bruising of some kernels, contributing to grain defects and making the grain more susceptible to insect and mould attacks. Contamination during threshing was also reported to be a significant problem. Groundnuts were predominantly shelled manually using hands, which is rather labour intensive and time consuming. It was noted that losses occurred when mechanical shelling was not followed by hand-stripping of the grains that are missed. Focus group discussion revealed that available shellers damage the grain, making insect penetration easier. This calls for improvement in the design of shellers available in the communities. For grains, threshing losses occurred as a result of spillage, incomplete removal of the grain or by damage to grain during the threshing. They also occurred after threshing due to poor separation of grain from the extraneous matter during cleaning or winnowing. Incomplete threshing usually occurred in households with high labour costs, particularly at harvest time. These findings point to the need to redesign existing technologies to improve their performance or to design new machines capable of higher grain recovery and lower grain damage. There is also need for more labour saving technologies for crops not yet covered by existing ones.

\subsection{Winnowing}

All farmers (100\%) reported use of manual methods. Apart from the long-time

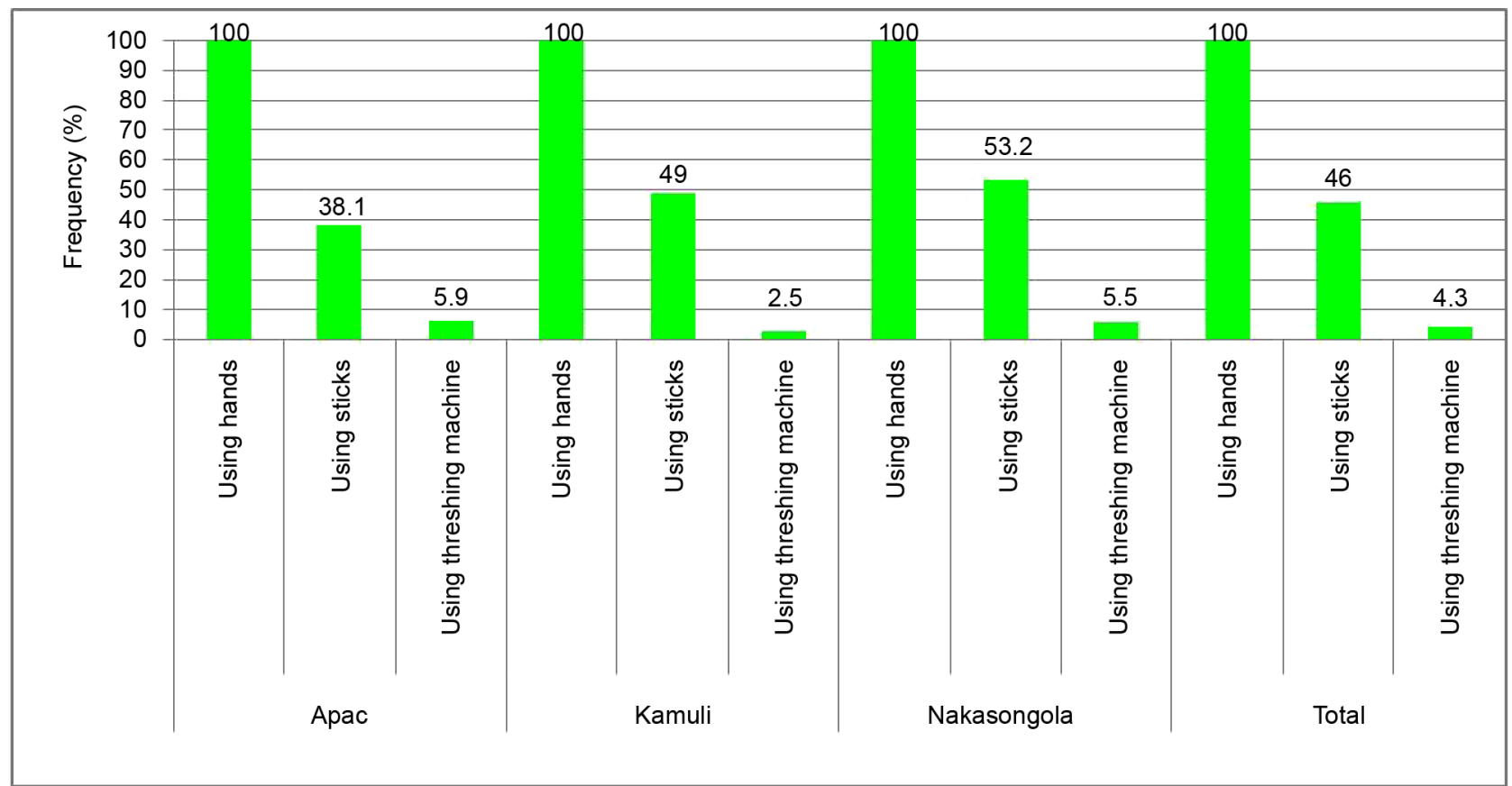

Figure 2. Methods used in threshing produce. 
taken by manual winnowing, this exposes farmers to ill health resulting from inhalation of dust. This finding points to a need to promote mechanized methods of winnowing. In addition to reducing drudgery, mechanized winnowers may be designed to reduce exposure of operators to dust inhalation.

\subsection{Storage}

Farmers generally stored produce in forms that are associated with extending shelf life. Groundnuts were predominantly stored in pods, maize on-cob, and dry cassava as chips and not flour (Table 5). In some cases large grains such as beans and groundnuts were stored mixed with small grains such as millet and sorghum. Focus group discussions and key informant interviews revealed that a limited proportion of farmers mixed grains with plants believed to be protective against insects and other biological postharvest hazards. The plants used include neem tree (Azadirachta indica), Lantana camara and red peppers (Capscum $s p p$ ). Other practices identified include mixing grain with husks before storage in bags. It is believed that the husks abrade and absorb insects' cuticle wax leading to dehydration of the insects causing death [11]. Statistical analysis however did not reveal a significant difference in reported storage loss for beans stored with husks and those without. Use of fine ash or other inert dusts like coarse,

Table 5. Percentage of farmers using different forms of storage.

\begin{tabular}{|c|c|c|}
\hline Crop & Form of storage & Overall \\
\hline \multirow[t]{2}{*}{ Maize } & $\mathrm{Cob} /$ Un threshed & 73.9 \\
\hline & Grains/Threshed & 26.1 \\
\hline \multirow[t]{2}{*}{ Millet } & Seed head/Un threshed & 80.2 \\
\hline & Grains/Threshed & 19.8 \\
\hline \multirow[t]{2}{*}{ Sorghum } & Seed head/Un threshed & 81.4 \\
\hline & Grains/Threshed & 18.6 \\
\hline \multirow[t]{2}{*}{ Grain amaranth } & Un threshed & - \\
\hline & Grains/Threshed & 100 \\
\hline \multirow[t]{2}{*}{ Beans } & Grains/Without pods & 83 \\
\hline & With pods & 17 \\
\hline \multirow[t]{2}{*}{ G. nuts } & Unshelled & 90.2 \\
\hline & Grains/Shelled & 9.8 \\
\hline \multirow[t]{2}{*}{ Cow peas } & Grains/Without pods & 100 \\
\hline & With pods & - \\
\hline \multirow[t]{2}{*}{ S. potatoes } & Fresh tubers & 71.7 \\
\hline & Dried chips & 28.3 \\
\hline \multirow[t]{2}{*}{ Cassava } & Fresh roots & 69.2 \\
\hline & Dried chips & 30.8 \\
\hline
\end{tabular}


clean sand was also practiced in Kamuli by a few farmers. The proportion of these inert dusts should be big enough to cover up all the spaces. According to focus groups, dust and other low particle size materials block inter-granular spaces between the grains, restricting respiration and movement of the bruchids [11]. The inert dust also limits oviposition by the bruchids.

One major observation from the survey was the limited use of stores. It was found that produce was mainly stored within the residential houses, including in bed rooms, kitchens and living rooms (Table 6). Safety from theft was apparently the main reason for this.

Farmers reported use of a diverse storage conditions (Table 7). Some of the reported conditions such as placing bagged grain directly on the floor are inappropriate and contribute to moisture uptake hastening deterioration. Storage in

Table 6. Proportion of farmers storing food items in different places.

\begin{tabular}{ccccccc}
\hline Crop & $\begin{array}{c}\text { Living } \\
\text { room }\end{array}$ & Kitchen & Bedroom & $\begin{array}{c}\text { Separate } \\
\text { store house }\end{array}$ & $\begin{array}{c}\text { Crib/ } \\
\text { granary }\end{array}$ & $\begin{array}{c}\text { Underground storage } \\
\text { (un-harvested) }\end{array}$ \\
\hline Maize & 12 & 30.4 & 57.6 & - & - & - \\
Millet & - & 21.9 & 68.7 & - & 9.4 & - \\
Sorghum & - & 27.1 & 60 & 2.9 & 10 & - \\
G. amaranth & 20.8 & - & 79.2 & - & - & - \\
Beans & 22.3 & 18.7 & 45.1 & - & 13.9 & - \\
G. nuts & - & 51.2 & 34.2 & - & 14.6 & - \\
C. peas & - & - & 100 & - & - & - \\
S. potatoes & - & 28 & 10.1 & - & 61.9 & 27.1 \\
Cassava & - & 40.3 & 26 & - & 33.7 & 100 \\
\hline
\end{tabular}

Table 7. Containers for storage of the various crops.

\begin{tabular}{cccccccc}
\hline Crop & Basket & $\begin{array}{c}\text { Metal } \\
\text { bin }\end{array}$ & $\begin{array}{c}\text { Brick } \\
\text { bin }\end{array}$ & $\begin{array}{c}\text { Bags on } \\
\text { floor }\end{array}$ & $\begin{array}{c}\text { Bags on } \\
\text { raised palate }\end{array}$ & Jerry-can & $\begin{array}{c}\text { No container } \\
\text { (on floor) }\end{array}$ \\
\hline Maize & - & - & - & 57.6 & 12 & - & 30.4 \\
Millet & 9.4 & - & - & 68.7 & - & - & 21.9 \\
Sorghum & 10 & - & 2.9 & 60 & - & - & 27.1 \\
G. amaranth & - & - & - & 79.2 & 20.8 & - & - \\
Beans & 13.9 & - & - & 38 & 22.3 & 7.1 & 18.7 \\
G. nuts & 14.6 & 1.5 & - & 23.4 & - & 9.3 & 51.2 \\
C. peas & - & - & - & 100 & - & - & - \\
S. potatoes & 61.9 & - & - & 10.1 & - & - & 28 \\
Cassava & 33.7 & - & - & 26 & - & - & 40.3 \\
\hline
\end{tabular}


baskets, which was also common, exposes produce to insect and rodent infestation.

Safety of the produce from theft is evidently an important consideration in farmers' choice of storage methods. Any storage interventions should therefore take this into consideration.

\subsection{Knowledge}

Oddly, there were indications from key informant interviews and focus group discussions that farmers' knowledge on most of the post-harvest processes was fairly good. It was noted for instance that the majority of farmers were aware of the benefits of using tarpaulins or raised platforms in drying crops but fewer than $20 \%$ reported practical use of the same. The majority (54\%) of farmers reported that they had received information on postharvest handling of food from non-governmental organization extension staff, $16.5 \%$ from other farmers and $4.1 \%$ from radio while $25.4 \%$ had not received any structured information about postharvest handling. None of the respondents identified government extension agents as source of postharvest information, pointing to a need to sensitize government extension personnel about the importance of proper postharvest handling. The low numbers of farmers using the information they have to improve the value of harvested crops points to the need to assess underlying factors affecting the use of different postharvest handling interventions. The existence of different players disseminating postharvest handling knowledge calls for building synergies of these players to enable farmers effectively benefit from all of them.

\subsection{Postharvest Handling Facilities}

From the survey, it is clear that farmers in the 3 districts lack the basic facilities required for proper postharvest handling of crops, right from harvesting to processing. Farmers are almost exclusively dependent on traditional facilities which are rather laborious. A number of postharvest handling equipment have been introduced to farmer, including cribs/granaries, maize shellers, chipping/grating machines, drying racks and milling machines. The adoption of these technologies is, however, still limited. The reasons identified for limited adoption included high cost of hiring technologies; difficulty in transporting machines; high capital investment; low prices offered for produce; limited access to technologies and spare parts; high running and/or maintenance costs of machines; high competition among users; inappropriateness of some machines for women users; accident proneness; threat of theft in case of cribs; limited volumes of produce harvested by individual farmers and low output for manual groundnut shellers. Evident from these findings is the need to assess the social aspects that promote or hinder the uptake and use of proven technologies. There is need to explore adapting these interventions to the needs and financial attainability of the different users. 


\subsection{Factors Associated with Poor Quality and High Postharvest Losses}

Based on statistical analysis of questionnaire data and synthesis of information collected from key informants interviews and focus group discussions, qualitative and quantitative postharvest losses in the study areas are associated with low level of education attained; not using drying materials like tarpaulins; mixed variety of seed used at planting; mixing new and old seeds as planting materials and improper forms of storage of produce. Apparently, there is no incentive for farmers to maintain high quality produce as quality produce does not necessarily attract better market prices. Other factors identified to contribute to postharvest losses include: poor post-harvest handling and storage facilities; theft; bad weather; unscrupulous nature of middle men; lack of unity among the farmers; lack of market information on prices; unfavorable costs associated with procurement of items; limited access to credit and information; heavy workload for the typical rural woman; poor post-harvest handling and inadequate on-farm storage facilities.

These findings point to the fact that many factors contribute to the quality and postharvest losses of the farmers' produce and to the need for a multi-dimensional approach in designing and developing interventions to improve quality and reduce postharvest losses. Building synergies of different players in postharvest handling and quality improvement will be relevant in this regard to tackle the different influencing factors.

\section{Conclusions}

Farmers seem to understand the problem of quantitative food loss during different stages of postharvest handling. Information collected from individual farmer interviews, key informants interviews and focus group discussions, shows that postharvest losses in the study areas are associated with inappropriate postharvest practices. Drying produce on bare ground seems almost ubiquitous and yet reasonably inexpensive options such as tarpaulins, mats, and racks made from local materials exist. The limited adoption of such interventions could be arising from the lack of incentive for farmers to maintain high quality produce as quality produce does not necessarily attract better market prices. Given the food safety problems associated with poorly handled food, it is important to sensitize different value chain actors to cause demand for quality food.

The gap between postharvest knowledge and practice points to a need for adaptive studies to develop technologies and promotion approaches most suited to the target communities. The study also revealed the predominance of manual processes in the postharvest handling of the different crops. To save farmers from drudgery, there is need for efforts to design and/or promote labor saving technologies. This is particularly important given that some of the labor intensive postharvest handling processes also damage the food material. 


\section{Acknowledgements}

This study was funded by McKnight Foundation under the Collaborative Crop Research Programme.

\section{References}

[1] Adeoye, I.B., Odeleye, O.M.O., Babalola, S.O. and Afolayan, S.O. (2009) Economic Analysis of Tomato Losses in Ibadan Metropolis, Oyo State, Nigeria. African Journal of Basic and Applied Sciences, 1, 87-92.

[2] Buyukbay, E.O., Uzunoz, M. and Sibel Gulse Bal, H. (2011) Post-Harvest Losses in Tomato and Fresh Bean Production in Tokat Province of Turkey. Scientific Research and Essays, 6, 1656-1666.

[3] Kaaya, N.A. and Warren, H.L. (2005) A Review of Past and Present Research on Aflatoxin in Uganda. African Journal of Food Agriculture Nutrition and Development, 5, 4-6.

[4] von Grebmer, K., Torero, M., Olofinbiyi, T., Fritschel, H., Wiesmann, D., Yohannes, Y., Schofield, L. and von Oppeln, C. (2011) Global Hunger Index. The Challenge of Hunger: Taming Price Spikes and Excessive Food Price Volatility. Deutsche Welthungerhilfe, International Food Policy Research Institute, and Concern Worldwide, Bonn, Washington, DC, and Dublin.

[5] Ministry of Agriculture, Animal Industry and Fisheries (2010) Agriculture Sector Development Strategic and Investment Plan (2010/11-2014/15). Kampala, Uganda.

[6] FAO (2011) Global Food Losses and Food Waste-Extent, Causes and Prevention. FAO, Rome.

[7] Nunnally, J.C. and Bernstein I.H. (1994) Psychometric Theory. $3^{\text {rd }}$ Edition, McGraw-Hill, New York.

[8] AOAC International (1999) Official Methods of Analysis of AOAC International. 6th Edition, 5th Revision, Vol. 11, AOAC International Publishers, Gaithersburg, MD.

[9] Pitt, J.I. and Hocking, A.D. (1997) Methods for Isolation, Enumeration and Identification. In: Fungi and Food Spoilage, Springer, Boston, MA, 21-57. https://doi.org/10.1007/978-1-4615-6391-4_4

[10] Uganda National Bureau of Standards (UNBS) (2011) Final Draft Uganda Standard. Sorghum Grains-Specification. FDUS EAS 757:2013.

[11] Kerruish, R.M., and Unger, P.W. (2010) Plant Protection 1-Pests, Diseases \& Weeds. Fourth Edition, RootRot Press, Hughes, Australia. 